\title{
Impact of a Trauma Intervention on Reducing Dropout from Substance Use Disorder Treatment
}

José J. López-Goñi ${ }^{1,2}$, Begoña Haro ${ }^{1,2}$, Javier Fernández-Montalvo ${ }^{1,2}$, Alfonso Arteaga $^{1,2}$

${ }^{1}$ Department of Health Sciences. Universidad Pública de Navarra

${ }^{2}$ IdiSNA, Instituto de Investigación Sanitaria de Navarra

Corresponding Author: José J. López-Goñi. Department of Health Sciences.

Universidad Pública de Navarra, Campus de Arrosadía, 31006 Pamplona, Spain.

Email: josejavier.lopez@unavarra.es

Research support: This study was supported by a grant (code PSI2016-76511-R) from the Agencia Estatal de Investigación (AEI) of the Spanish Government and Fondo Europeo de Desarrollo Regional of the European Union (FEDER, EU).

Acknowledgements: The authors thank the "Proyecto Hombre Navarra" and "ANTOX" programme staff for their help with assessing the clinical sample.

Conflict of Interest: The authors do not have any financial interests that may be interpreted as influencing the research.

(C) 2021, American Psychological Association. This paper is not the copy of record and may not exactly replicate the final, authoritative version of the article. Please do not copy or cite without authors' permission. The final article will be available, upon publication, via its DOI: $10.1037 /$ tra0001127

López-Goñi, J. J., Haro, B., Fernández-Montalvo, J., \& Arteaga, A. (2021). Impact of a trauma intervention on reducing dropout from substance use disorder treatment. Psychological Trauma: Theory, Research, Practice, and Policy. Advance online publication. 


\begin{abstract}
Objective: To evaluate the effectiveness (in terms of retention) of an intervention aimed at treating the consequences of lifetime physical and/or sexual abuse among patients who are also seeking substance use disorder treatment (SUD-T) in a clinical centre. Method: A parallel, randomized, controlled clinical trial using an experimental design (with one treatment group and one control group) with repeated measures (pretreatment, posttreatment and 6-month follow-up) was carried out. The sample consisted of 57 patients in SUD-T who had experienced lifetime physical and/or sexual abuse. All patients received a cognitive-behavioural SUD-T. In addition, the treatment group $(n=$ 29) received physical and/or sexual abuse treatment (PSA-T). Results: The treatment group presented a lower SUD-T dropout rate $(37.9 \% ; n=11)$ than the control group
\end{abstract} $(50.0 \% ; \mathrm{n}=14)$, but this difference was not statistically significant $\left(\chi^{2}=0.8 ; \mathrm{p}=.359\right.$; $\mathrm{Phi}=.122$ ). The main variable related to SUD-T success (therapeutic discharge after completing the 40 outpatient sessions or 12 inpatients months and maintained abstinence) was the completion of PSA-T. Conclusions: The completion of this traumacentred treatment improved the retention rate of SUD-T in patients with histories of physical and/or sexual abuse. This is a promising result because of the high SUD-T dropout rate shown by patients with victimization.

Keywords: randomized controlled trial; trauma intervention; substance use disorder; psychopathology; dropout rate

\title{
Clinical Impact Statement
}

The present study suggests that a centred-trauma intervention improves substance use disorder treatment retention in patients who have suffered lifetime physical and or sexual abuse. Additionally, interference of trauma in daily life and psychopathological 
symptomatology decreases in patients who receive interventions for both trauma and substance use disorder simultaneously. This evidence supports the need of centredtrauma interventions in substance use disorder treatment programmes to improve therapeutic results in these patients. 


\section{Impact of a Trauma Intervention on Reducing Dropout from Substance Use Disorder Treatment}

The relationship between having experienced a traumatic event and developing a substance use-related problem is well established (Haller \& Chassin, 2014; Khantzian, 1997). The prevalence of abuse is higher among patients in substance use disorder treatment (SUD-T) than in the general population (Jakubczyk et al., 2014; Olaya et al., 2015). The rates of physical abuse in patients with substance use disorder range from $18.0 \%$ to $53.7 \%$ (Fernández-Montalvo et al., 2015; Grundmann et al., 2018) and, in the case of sexual abuse, from $9.2 \%$ to $31.7 \%$ (Fernández-Montalvo et al., 2015;

Fernández-Montalvo et al., 2017). Compared to patients without a history of abuse, patients who have experienced these traumatic events present a worse psychopathological profile and higher rates of treatment dropout (Brems et al., 2004; Daigre et al., 2015; López-Goñi et al., 2018). These specific characteristics could be associated with specific treatment needs (Parisi et al., 2020).

The convenience of addressing trauma-related problems in SUD-T patients has been widely discussed (Echeburúa, 2004). Studies analysing the effectiveness of combined interventions for SUD-T and physical and/or sexual abuse are scarce. Most researchers have focused on the specific subsample of individuals with comorbid posttraumatic stress disorder (PTSD) and substance use disorder. Simpson et al. (2017) reported that SUD-T decreased PTSD symptomatology. This improvement is greater when SUD-T includes a trauma-centred cognitive-behavioural treatment (Roberts et al., 2015). Currently, this therapy is recommended for PTSD patients (Hamblen et al., 2019) and also for patients with concurrent PTSD and substance use disorder (Flanagan 
et al., 2016). However, there are likely other trauma-related symptoms, in addition to PTSD, related to SUD-T difficulties that have not been addressed.

Traumatic experiences are an important risk factor for numerous mental health consequences in addition to PTSD (Schneider et al., 2008). For example, childhood maltreatment is related to the development of varied adult psychopathology (Jewkes et al., 2010), suicidal ideation (Brodsky \& Stanley, 2001), and substance use (Asgeirsdottir et al., 2011). The lack of emotional regulation and the use of avoidant coping strategies are mediators between physical and/or sexual abuse and the development of a substance use disorder (Khosravani et al., 2019; Sullivan et al., 2017). Given the high rates of histories of abuse between SUD-T patients, the development of patient-centred interventions seems recommendable. The application of SUD-T without a trauma-centred treatment in this population may jeopardize the treatment results. There is a gap in effective treatments for patients in SUD-T with histories of physical and/or sexual abuse (Schneider et al., 2008). A recent meta-analysis Parisi et al. (2020), did not find that a history of sexual victimization was associated with SUD-T dropout. Nonetheless, this revision identified important gaps in the literature such as the small number of adequate and updated investigations to obtain valid results and the need to use standardized measures to evaluate sexual abuse. It is recommended to fulfil these gaps and develop longitudinal designs to improve the knowledge of the relationships between sexual abuse and SUD-T dropout.

Consequently, the main purpose of this study was to evaluate the effectiveness in terms of retention of a psychological treatment aimed at the consequences of physical and/or sexual abuse (PSA-T) among patients seeking SUD-T in a clinical centre. Specifically, a combined intervention for substance use disorder and physical and/or 
sexual abuse consequences was compared with SUD-T as usual. The main hypotheses of this study were that patients receiving the combined SUD-T and PSA-T would achieve (a) a lower rate of dropout in SUD-T than patients receiving only SUD-T and (b) greater improvement in psychopathological, impulsiveness, and maladjustment variables than patients who received only SUD-T.

\section{Methods}

\section{Participants}

The sample consisted of 496 patients seeking treatment for substance use disorder in the Proyecto Hombre Navarra (inpatient and outpatient) and ANTOX (inpatient) addiction programmes in Navarra (Spain) between February 2017 and June 2019. These programmes are cognitive behavioural based and are geared towards abstinence. The inclusion criteria to the study were as follows: a) meeting the diagnostic criteria for substance use disorder according to the DSM-5 (American Psychiatric Association, 2013); b) having suffered histories of physical and/or sexual abuse; c) being older than 18 years old; d) being at the beginning stages of SUD-T; and e) giving consent to participate in the study. The exclusion criteria included a) the existence of serious mental illness advising against participation in the study (e.g., psychotic disorders) and b) a lack of knowledge of the Spanish language.

Due to the abovementioned inclusion and exclusion criteria, 439 people (88.5\%) were excluded from the study, mainly for not having a history of physical and/or sexual abuse. Therefore, a total of 57 (11.4\% of the total) subjects were included (Figure 1). Of these subjects, $54.4 \%(n=31)$ were men, and $45.6 \%(n=26)$ were women. The patients were randomly assigned to one of two groups: the treatment group $(n=29 ; 21$ inpatient and 8 outpatient) or the control group ( $n=28 ; 21$ inpatient and 7 outpatient). Both 
groups were homogeneous regarding sociodemographic variables, substance motivating treatment, and type of abuse (Table 1). A more detailed description of the sample characteristics can be found in Haro et al. (2021).

\section{PLACE TABLE 1 AND FIGURE 1 HERE}

\section{Instruments}

The family/social area of the EuropASI (Kokkevi \& Hartgers, 1995; Spanish version by Bobes et al., 1996), the European version of the Addiction Severity Index (McLellan et al., 1980), was used for the assessment of lifetime abuse. In this study, two specific items were used: 18B (Has anyone ever physically abused you?) and 18C (Has anyone ever sexually abused you?). The EuropASI is a semistructured interview that assesses the need for treatment in patients with substance use disorder. The short-term test-retest reliabilities of the ASI severity ratings have been reported to be greater than or equal to .92 for all domains (McLellan et al., 1985).

The Severity Posttraumatic Stress Disorder Scale - Revised (EGS-R; Echeburúa et al., 2016) is a Spanish semistructured interview that helps the clinician to evaluate the presence and severity of PTSD symptomatology and diagnosis. It is based on the diagnostic criteria of the DSM-5. It is composed of two parts: the first part evaluates the exposure to a traumatic event, and the second part assesses the severity and frequency of PTSD symptoms. Given the aim of this study, the intensity and severity of traumarelated symptoms were utilized for these data vs. the absence/presence of a PTSD diagnosis. It consists of 21 items scored from 0 (nothing/never) to 3 (extremely/5 or more times a week) on a four-point Likert scale. In addition, six items valorise the interference of trauma in different daily life areas. The internal consistency is 0.91 .

López-Goñi, J. J., Haro, B., Fernández-Montalvo, J., \& Arteaga, A. (2021). Impact of a trauma intervention on reducing dropout from substance use disorder treatment. Psychological Trauma: Theory, Research, Practice, and Policy. Advance online publication. 
The Symptom Checklist (SCL-90-R) (Derogatis, 1992) is a self-report tool that assesses psychopathological symptoms. It is composed of 90 items that are answered on a five-point Likert scale, from 0 (nothing) to 4 (extremely). This tool aims to assess the symptoms of psychological distress. It consists of nine primary symptom dimensions (somatization, obsession-compulsion, interpersonal sensitivity, depression, anxiety, hostility, phobic anxiety, paranoid ideation, and psychoticism) and three global indices of severity: the Global Severity Index (GSI), which reflects overall symptom severity; the Positive Symptom Distress Index (PSDI), which indicates symptom intensity; and the Positive Symptom Total (PST), which includes the number of items answered with a score different from 0 . The internal consistency ranges from .70 to .90 . In this study, the percentiles of each dimension were considered.

The Barratt Impulsiveness Scale (BIS-10; Barratt, 1985) aims to assess the degree of impulsiveness of the subject. It consists of 33 items that are scored from 0 (nothing) to 4 (extremely) on a five-point Likert scale. The total score ranges from 0 to 132. This tool provides information about three different dimensions of impulsiveness: motor, cognitive, and non-planning. The internal consistency is .84 . This instrument has been found to be valid to ensure impulsiveness in the Spanish population (Oquendo et al., 2001).

The Maladjustment Scale (MS; Echeburúa, Corral, \& Fernández-Montalvo, 2000) reveals how each patient is affected in six different areas of everyday life: labour, social, leisure, partner, family and general. Each area ranges from 0 (nothing) to 5 (extremely) on a six-point Likert scale. The total scale range is $0-30$. Higher scores indicate higher levels of maladjustment. The internal consistency is .94.

\section{Treatment Modalities}

López-Goñi, J. J., Haro, B., Fernández-Montalvo, J., \& Arteaga, A. (2021). Impact of a trauma intervention on reducing dropout from substance use disorder treatment. Psychological Trauma: Theory, Research, Practice, and Policy. Advance online publication. 


\section{Substance Use Disorder Treatment (SUD-T)}

This intervention is based on a cognitive-behavioural model and is composed of two different modalities (outpatient and inpatient treatment) aimed towards abstinence. The main therapeutic techniques are related to stimulus control and in vivo exposure, as well as relapse prevention. The professionals that provided both modalities were clinical psychologists with 10 or more years of experience in assessing and treating substance use disorder. The outpatient modality includes weekly sessions (45-60 minutes) during the first 6 months and biweekly sessions for the following 6 months. The therapists carry out urine analyses periodically to verify substance abstinence. The programme completion in both modalities usually takes 12 months (about 40 sessions in the case of outpatient treatment). Therapeutic success is reached when a patient completes all therapeutic sessions and achieves substance abstinence. Both outpatient and inpatient modalities have been effective in the treatment of addiction (Fernández-Montalvo et al., 2008; Fernandez-Montalvo \& López-Goñi, 2010).

\section{Physical and/or Sexual Abuse Treatment (PSA-T)}

PSA-T is a cognitive-behavioural trauma-centred treatment. This programme is composed of 10 weekly individual or group sessions lasting 60 minutes or 90 minutes, respectively. When it is possible to gather more than one patient, it is provided in group. Individual $(n=19)$ or in group $(n=10)$ modalities are equivalent. All patients receive the same content with the same therapeutic techniques. In the case of inpatient SUD-T, PSA-T is provided while patients are hospitalized. PSA-T includes the cognitive restructuring of distortions related to the traumatic event and aims to facilitate the expression of negative emotions. The treatment is focused on traumatic symptoms and the maladjustment they cause in daily life. PSA-T aims to teach patients adaptive 
coping strategies. It is based on the intervention programme developed by Echeburúa $\&$ Corral (1998) and has been effective in the treatment of physical and sexual abuse (Echeburúa et al., 1996). A summary of the specific components of the treatment programme is provided in Table 2. PSA-T and SUD-T were provided simultaneously; PSA-T was received as an additional component of their SUD-T.

\section{PLACE TABLE 2 HERE}

\section{Experimental Design}

This study consists of a parallel, randomized, controlled clinical trial using an experimental design (with one treatment group and one control group) with repeated measures (pretreatment, posttreatment and 6-month follow-up).

The ethics committees of the Universidad Pública de Navarra (PI-006/16), Proyecto Hombre Navarra (PHN2016-01), and ANTOX approved the protocol for this study. All participants signed informed consent forms.

\section{Procedure}

All patients were interviewed by clinical psychologists who specialized in the assessment and treatment of addictions and trauma. The assessment of the sample was carried out in two sessions at the beginning of the addiction treatment. During the first session, sociodemographic data and physical and/or sexual abuse variables were evaluated. A more in-depth interview was carried out with patients who reported a history of physical and/or sexual abuse. In the second session, the remaining instruments were completed. Self-report measures were administered with the presence and support of the interviewers.

After the clinical sample was assessed, the patients were randomly assigned using a table of random numbers to one of two groups: the treatment group $(n=29)$ or 
the control group $(n=28)$. All patients received a cognitive-behavioural SUD-T. In addition, the treatment group received the specific PSA-T. Once PSA-T was carried out, all participants completed the posttreatment assessment. Six months later, both groups were assessed in the follow-up evaluation. In this study, treatment success was defined as completion of SUD-T.

Both groups were assessed at the same time points. The treatment group underwent SUD-T and PSA-T simultaneously. This global treatment (SUD-T + PSA-T) was cohesive, as both interventions were based on a cognitive-behavioural model, and therapists gave a consistent and complementary treatment for both conditions in the same treatment programme. The control group underwent only SUD-T.

\section{Data Analysis}

An intention-to-treat analysis was carried out and included all randomized subjects in the groups to which they were allocated, with no deviations from randomized allocation being observed. Descriptive analyses were conducted for all variables. In the bivariate analyses, comparisons between the groups were performed using $\chi^{2}$ or Student's $t$-test for independent samples, depending on the nature of the variables analysed. Effect sizes (Cohen's $d$ or Phi coefficient) were provided depending on the nature of the analyses. Repeated measures ANOVAs with Bonferroni adjustment were carried out to evaluate changes in the continuous variables. Moreover, a logistic regression analysis was conducted to determine which pretreatment variables (treatment/control group, alcohol as substance motivating treatment, physical/sexual abuse, EGS-R total, SCL-90-R-GSI, BIS-10 and MS) were the most relevant for differentiating SUD-T completion. In addition, another logistic regression analysis was conducted including PSA-T completion (PSA-T completion vs. PSA-T no completion + 
control group) as an independent variable. The variable entry criterion was set to 0.05 , and the variable retention criterion was set to 0.10 . Moreover, the Hosmer-Lemeshow test was used to assess the goodness of fit of these models. A difference of $p<.05$ was considered significant. All statistical analyses were performed using SPSS (version 25.0) software.

\section{Results}

\section{Rates of Treatment Dropout}

The rate of SUD-T dropout was $37.9 \%(n=11)$ in the treatment group and $50.0 \%(n=14)$ in the control group. No statistically significant differences were found $\left(\chi^{2}=0.8 ; p=.359 ; \mathrm{Phi}=.122\right)$.

The rate of PSA-T dropout was $13.8 \%(n=4)$. The rate of SUD-T dropout was $28.0 \%(n=7)$ in patients who completed PSA-T and $100 \%(n=4)$ in patients who did not complete PSA-T, with significant differences between groups $\left(\chi^{2}=4.8 ; p=.028\right.$; Phi $=.512)$.

\section{Variables Related to SUD-T Completion}

In the first analysis of logistic regression (related to pretreatment assessment), no variables related to SUD-T completion were found. The results of the second analysis showed that having completed PSA-T was the only variable related to SUD-T completion (Table 3 ). This variable correctly classified $63.2 \%$ of all participants.

\section{PLACE TABLE 3 HERE}

\section{Results for Psychopathological, Personality and Maladjustment Variables}

Differences between groups are presented in Table 4. The treatment group achieved lower global maladjustment than the control group at posttreatment $(t=2.5 ; p$ $=.014)$ and at the follow-up $(t=3.0 ; p=.006)$. The treatment group also achieved better 
results in several variables at the follow-up: interference of posttraumatic symptom consequences in daily life $(t=2.6 ; p=.014)$, global psychopathological symptom severity $(t=2.2 ; p=.034)$ and symptom intensity $(t=2.2 ; p=.029)$.

\section{PLACE TABLE 4 HERE}

The ANOVA results for repeated measurements of the studied variables are presented in Table 5. Both groups achieved statistically significant improvement in most of the variables. The variables in which only the treatment group presented a statistically significant improvement were interference of posttraumatic symptoms consequences in daily life from post-treatment to follow-up $(t=2.4 ; p=.027)$, PSDI from SCL-90-R between pretreatment and follow-up $(t=5.6 ; p<.000)$, global impulsivity from pre to post-treatment $(t=2.7 ; p=.010)$ and global maladjustment from post-treatment to follow-up $(t=2.3 ; p=.032)$.

\section{PLACE TABLE 5 HERE}

\section{Discussion}

The main contribution of this study is that this is the first randomized controlled trial in Spain that evaluates a trauma-centred treatment in SUD-T patients with histories of physical and/or sexual abuse. In this study, the completion of a trauma-centred treatment improved the retention rate of this population. However, the results were not statistically significant; therefore, the first hypothesis is not confirmed. Different factors might explain this result. Most of dropouts in SUD-T occur during the first three months. An adequate strategy to avoid dropouts is based on matching patients' needs with the treatment provided (Bourion-Bédès et al., 2020). In fact, a recent study with women in outpatient SUD-T with PTSD recommended that treatments should be adapted to the abstinence status of patients (Grundmann et al., 2021). This specific issue 
has not been addressed in the present study and could be considered in the future.

Anyway, this is a promising result because of the high SUD-T dropout rates shown by patients with victimization histories (Fernández-Montalvo et al., 2015).

As reported previously (Coffey et al., 2016; Ruglass et al., 2017; Simpson et al., 2017), the results of the current study indicate that patients who received SUD-T experienced improvement in all areas, including those related to trauma. Patients who additionally received specific PSA-T showed greater improvement than those without this additional treatment aimed at the abuse, as hypothesized. Similar to previous studies, interference of trauma symptoms in daily life areas and global psychopathology have decreased in follow-up assessments (Coffey et al., 2016; Roberts et al., 2015; Tirado-Muñoz et al., 2015). This aspect is very promising because PSA-T is relatively easy to implement in only 10 sessions. Moreover, although the global rate of SUD-T dropout was similar to previous research (Fernández-Montalvo et al., 2015), patients who completed PSA-T showed a lower rate of dropout. In fact, the main variable related to SUD-T completion was the finalization of PSA-T.

This evidence supports the need for SUD-T programmes to provide traumacentred treatments. In the case of patients who have experienced physical and/or sexual abuse, the intervention in trauma-related consequences in daily life seems adequate in SUD-T, and it improves SUD-T completion. In the future, it will be necessary to investigate whether this improvement is related to lower rates of relapse. Some patients in SUD-T are readmitted to treatment programmes multiple times because of relapses that occur after they leave these programmes. This could be due to the presence of problems or difficulties that were not satisfactorily solved or addressed during previous 
treatment periods (López-Goñi et al., 2014) such as PTSD. PSA-T may address this deficit and achieve better results in patient progression.

The generalization of these results to all patients with substance use disorders must be done cautiously because the sample of this study was composed of patients receiving treatment in two specific SUD-T programmes in Spain. Moreover, a drawback of this study is the limited size of the sample. This is related to the difficulty in enrolling patients with a history of PSA in SUD treatments. Patients with PSA could dropout more probably than those without PSA in early stages of treatment. In this sense, the presence of PSA could be a selection bias in SUD treatments. The inclusion of traumainformed practice in SUD treatment centres could address this bias. In any case, it would be interesting to achieve larger samples. Moreover, this could allow us to analyse the interaction of different variables (e.g., type of abuse or gender) with SUD-T dropout. Another limitation is related to the different treatment doses received by both groups (the treatment group received an additional treatment), which could generate potential spurious effects that should be considered when interpreting the results. Finally, a longer follow-up period would have allowed us to explore whether the results obtained remained the same over 6 months.

Despite these limitations, this study presents several strengths. The multimethod assessment approach (combination of self-reports and face-to-face interviews) increases the value of this study. Moreover, SUD-T and PSA-T seem easy to provide because they are time-matched and have been effective in improving SUD-T retention. Finally, this is the first study in Spain of these characteristics, and it provides information that has not been addressed before.

López-Goñi, J. J., Haro, B., Fernández-Montalvo, J., \& Arteaga, A. (2021). Impact of a trauma intervention on reducing dropout from substance use disorder treatment. Psychological Trauma: Theory, Research, Practice, and Policy. Advance online publication. 


\section{References}

American Psychiatric Association. (2013). Diagnostic and statistical manual of mental disorders (5th ed.). American Psychiatric Press.

Asgeirsdottir, B. B., Sigfusdottir, I. D., Gudjonsson, G. H., \& Sigurdsson, J. F. (2011). Associations between sexual abuse and family conflict/violence, self-injurious behavior, and substance use: The mediating role of depressed mood and anger. Child Abuse and Neglect, 35(3), 210-219. https://doi.org/10.1016/j.chiabu.2010.12.003

Barratt, E. S. (1985). Impulsiveness subtraits: Arousal and information procesing. In J. T. S. y C. E. Itard (Ed.), Motivation, Emotion and Personality. Elsevier.

Bobes, J., Gónzález, M. P., Sáiz, P. A., \& Bousoño, M. (1996). Índice europeo de severidad de la adicción: EuropASI. Versión española. Actas de La IV Reunión Interregional de Psiquiatría.

Bourion-Bédès, S., Simirea, A., Di Patrizio, P., Müller, O., Clerc-Urmès, I., Sy, A., Schwan, R., Viennet, S., \& Baumann, C. (2020). Is early outpatient satisfaction with substance use disorder care a predictor of early dropout? Results of the SUBUSQOL cohort. Journal of Substance Abuse Treatment, 119, 108151. https://doi.org/10.1016/j.jsat.2020.108151

Brems, C., Johnson, M. E., Neal, D., \& Freemon, M. (2004). Childhood abuse history and substance use among men and women receiving detoxification services. The American Journal of Drug and Alcohol Abuse, 30(4), 799-821. https://doi.org/10.1081/ADA-200037546

Brodsky, B. S., \& Stanley, B. (2001). Developmental effects on suicidal behavior: The role of abuse in childhood. Clinical Neuroscience Research, 1(5), 331-336. https://doi.org/10.1016/S1566-2772(01)00034-2

López-Goñi, J. J., Haro, B., Fernández-Montalvo, J., \& Arteaga, A. (2021). Impact of a trauma intervention on reducing dropout from substance use disorder treatment. Psychological Trauma: Theory, Research, Practice, and Policy. Advance online publication. 
Coffey, S. ., Schumacher, J. ., Nosen, E., Littlefield, A. K., Henslee, A. M., Lappen, A., \& Stasiewicz, P. R. (2016). Trauma-focused exposure therapy for chronic posttraumatic stress disorder in alcohol and drug dependent patients: A randomized controlled trial. Psychology of Addictive Behaviors, 30(7), 778-790. https://doi.org/10.1037/adb0000201

Daigre, C., Rodríguez-Cintas, L., Tarifa, N., Rodríguez-Martos, L., Grau-López, L., Berenguer, M., Casas, M., \& Roncero, C. (2015). History of sexual, emotional or physical abuse and psychiatric comorbidity in substance-dependent patients. $\begin{array}{lll}\text { Psychiatry } \quad \text { Research, } & \text { 229(3), }\end{array}$ https://doi.org/10.1016/j.psychres.2015.08.008

Derogatis, L. R. (1992). The SCL-90-R. Clinical Psychometric Research.

Echeburúa, E., \& Corral, P. (1998). Manual de violencia familiar. Siglo XXI.

Echeburúa, E., Corral, P., \& Fernández-Montalvo, J. (2000). Escala de inadaptación (EI): Propiedades psicométricas en contextos clínicos. Análisis y Modificación de Conducta, 26(107), 325-340.

Echeburúa, E., Corral, P., Sarasua, B., \& Zubizarreta, I. (1996). Tratamiento cognitivoconductual del trastorno de estrés postraumático en víctimas de maltrato doméstico: un estudio piloto. Análisis y Modificación de Conducta, 22, 627-654.

Echeburúa, E, Amor, P. J., Sarasua, B., Zubizarreta, I., Holgado-Tello, F. P., \& Muñoz, J. M. (2016). Escala de Gravedad de Síntomas Revisada (EGS-R) del Trastorno de Estrés Postraumático según el DSM-5: propiedades psicométricas. Terapia Psicológica, 34(2), 111-128. https://doi.org/http://dx.doi.org/10.4067/S071848082016000200004

Echeburúa, Enrique. (2004). Superar un trauma. Ediciones Pirámide.

López-Goñi, J. J., Haro, B., Fernández-Montalvo, J., \& Arteaga, A. (2021). Impact of a trauma intervention on reducing dropout from substance use disorder treatment. Psychological Trauma: Theory, Research, Practice, and Policy. Advance online publication. https://doi.org/10.1037/tra0001127 
Fernandez-Montalvo, J., \& López-Goñi, J. J. (2010). Comparison of completers and dropouts in psychological treatment for cocaine addiction. Addiction Research \& Theory, 18(4), 433-441. https://doi.org/10.3109/16066350903324826

Fernández-Montalvo, J., López-Goñi, J. J., \& Arteaga, A. (2015). Psychological, physical, and sexual abuse in addicted patients who undergo treatment. Journal of Interpersonal $\quad$ Violence, $\quad 30(8), \quad 1279-1298$. https://doi.org/10.1177/0886260514539843

Fernández-Montalvo, J., López-Goñi, J. J., Arteaga, A., Cacho, R., \& Azanza, P. (2017). Therapeutic progression in abused women following a drug-addiction treatment program. Journal of Interpersonal Violence, 32(13), 2046-2056. https://doi.org/10.1177/0886260515591980

Fernández-Montalvo, J., López-Goñi, J. J., Illescas, C., Landa, N., \& Lorea, I. (2008). Evaluation of a therapeutic community treatment program: A long-term follow-up study in Spain. Substance Use \& Misuse, 43(10), 1362-1377. https://doi.org/10.1080/10826080801922231

Flanagan, J. C., Korte, K. J., Killeen, T. K., \& Back, S. E. (2016). Concurrent Treatment of Substance Use and PTSD. Current Psychiatry Reports, 18(8), 70. https://doi.org/10.1007/s11920-016-0709-y

Grundmann, J., Lincoln, T. M., Lüdecke, D., Bong, S., Schulte, B., Verthein, U., \& Schäfer, I. (2018). Traumatic experiences, revictimization and posttraumatic stress disorder in german inpatients treated for alcohol dependence. Substance Use and Misuse, 53(4), 677-685. https://doi.org/10.1080/10826084.2017.1361997

Grundmann, J., Lotzin, A., Sehner, S., Verthein, U., Hiller, P., Hiersemann, R., Lincoln, T. M., Hillemacher, T., Schneider, B., Driessen, M., Scherbaum, N., Dotten, A. C., intervention on reducing dropout from substance use disorder treatment. Psychological Trauma: Theory, Research, Practice, and Policy. Advance online publication. 
\& Schäfer, I. (2021). Predictors of attendance in outpatient group treatment for women with posttraumatic stress disorder and substance use disorder. Psychotherapy Research, 31(5), 632-643. https://doi.org/10.1080/10503307.2020.1817604

Haller, M., \& Chassin, L. (2014). Risk pathways among traumatic stress, posttraumatic stress disorder symptoms, and alcohol and drug problems: A test of four hypotheses. Psychology of Addictive Behaviors, 28(3), 841-851. https://doi.org/10.1037/a0035878

Hamblen, J. L., Norman, S. B., Sonis, J. H., Phelps, A. J., Bisson, J. I., Nunes, V. D., Megnin-Viggars, O., Forbes, D., Riggs, D. S., \& Schnurr, P. P. (2019). A guide to guidelines for the treatment of posttraumatic stress disorder in adults: An update. Psychotherapy, 56(3), 359-373. https://doi.org/10.1037/pst0000231

Haro, B., López-Goñi, J. J., Fernández-Montalvo, J., \& Arteaga, A. (2021). Prevalence and Differential Profile of Patients with Substance Use Disorder Who Have Suffered Physical and/or Sexual Abuse. Journal of Interpersonal Violence, 1-18. https://doi.org/10.1177/08862605211001463

Jakubczyk, A., Klimkiewicz, A., Krasowska, A., Kopera, M., Sławiń ska-Ceran, A., Brower, K. J., Wojnar, M., Sławińska-Ceran, A., Brower, K. J., \& Wojnar, M. (2014). History of sexual abuse and suicide attempts in alcohol- dependent patients. Child Abuse and Neglect, 38(9), 1560-1568. https://doi.org/10.1038/nbt.3121.ChIPnexus

Jewkes, R. K., Dunkle, K., Nduna, M., Jama, P. N., \& Puren, A. (2010). Associations between childhood adversity and depression, substance abuse and HIV and HSV2 incident infections in rural South African youth. Child Abuse and Neglect, 34(11), 
833-841. https://doi.org/10.1016/j.chiabu.2010.05.002

Khantzian, E. J. (1997). The self-medication hypothesis of substance use disorders: A reconsideration and recent applications. Harvard Review of Psychiatry, 4(5), 231244. https://doi.org/10.3109/10673229709030550

Khosravani, V., Ardestani, S. M. S., Bastan, F. S., Mohammadzadeh, A., \& Amirinezhad, A. (2019). Childhood maltreatment, cognitive emotion regulation strategies, and alcohol craving and dependence in alcohol-dependent males: Direct and indirect pathways. Child Abuse and Neglect, 98(September), 104197. https://doi.org/10.1016/j.chiabu.2019.104197

Kokkevi, A., \& Hartgers, C. (1995). European adaptation of a multidimensional assessment instrument for drug and alcohol dependence. European Addiction Research, 1, 208-210.

López-Goñi, J. J., Fernández-Montalvo, J., Arteaga, A., \& Haro, B. (2018). Suicidal ideation and attempts in patients who seek treatment for substance use disorder. Psychiatry Research, 269(March), 542-548. https://doi.org/10.1016/j.psychres.2018.08.100

López-Goñi, J. J., Fernández-Montalvo, J., Cacho, R., \& Arteaga, A. (2014). Profile of addicted patients who reenter treatment programs. Substance Abuse, 35(2), 176-183. https://doi.org/10.1080/08897077.2013.826614

McLellan, A., Luborsky, L., Cacciola, J., Griffith, J., Evans, F., Barr, H., \& O’Brien, C. (1985). New data from the Addiction Severity Index: reliability and validity in three centers. Journal of Nervous and Mental Disease, 173, 412-423.

McLellan, A. T., Luborsky, L., Woody, G. E., \& O’Brien, C. P. (1980). An improved diagnostic evaluation instrument for substance abuse patients. The Addiction intervention on reducing dropout from substance use disorder treatment. Psychological Trauma: Theory, Research, Practice, and Policy. Advance online publication. 
Severity Index. The Journal of Nervous and Mental Disease, 168(1), 26-33. https://doi.org/10.1097/00005053-198001000-00006

Olaya, B., Alonso, J., Atwoli, L., Kessler, R. C., Vilagut, G., \& Haro, J. M. (2015). Association between traumatic events and post-traumatic stress disorder: results from the ESEMeD-Spain study. Epidemiology and Psychiatric Sciences, 24(2), 172183. https://doi.org/10.1016/j.physbeh.2017.03.040

Oquendo, M., Baca-García, E., Graver, R., Morales, M., Montalban, V., \& Mann, J. (2001). Spanish adaptation of Barratt Impulsiveness Scale (BIS). European Journal of Psychiatry, 15, 147-155.

Parisi, A., Jordan, B., Jensen, T., \& Howard, M. O. (2020). The impact of sexual victimization on substance use disorder treatment completion : A systematic review and meta-analysis completion. Substance Abuse. https://doi.org/10.1080/08897077.2020.1748168

Roberts, N. P., Roberts, P. A., Jones, N., \& Bisson, J. I. (2015). Psychological interventions for post-traumatic stress disorder and comorbid substance use disorder: A systematic review and meta-analysis. Clinical Psychology Review, 38, 25-38. https://doi.org/10.1016/j.cpr.2015.02.007

Ruglass, L. M., Lopez-Castro, T., Papini, S., Killeen, T., Back, S. E., \& Hien, D. A. (2017). Concurrent treatment with prolonged exposure for co-occurring full or subthreshold posttraumatic stress disorder and substance use disorders: A randomized clinical trial. Psychotherapy and Psychosomatics, 86(3), 150-161. https://doi.org/10.1159/000462977

Schneider, R., Cronkite, R., \& Timko, C. (2008). Lifetime physical and sexual abuse and substance use treatment outcomes in men. Journal of Substance Abuse Treatment, intervention on reducing dropout from substance use disorder treatment. Psychological Trauma: Theory, Research, Practice, and Policy. Advance online publication. 
35(4), 353-361. https://doi.org/10.1016/j.jsat.2008.01.001

Simpson, T. L., Lehavot, K., \& Petrakis, I. L. (2017). No wrong doors: Findings from a critical review of behavioral randomized clinical trials for individuals with cooccurring alcohol/drug problems and posttraumatic stress disorder. Alcoholism: Clinical and Experimental Research, 41(4), 681-702. https://doi.org/10.1111/acer.13325

Sullivan, T. P., Weiss, N. H., Price, C., Pugh, N., \& Hansen, N. B. (2017). Strategies for coping with individual PTSD symptoms: experiences of African American victims of intimate partner violence. Psychological Trauma, 10(3), 336-344. https://doi.org/10.1037/tra0000283 


\section{Table 1}

Comparisons of Sociodemographic Characteristics, Substance Motivating Treatment, and Type of History of Abuse

\begin{tabular}{|c|c|c|c|c|c|c|c|c|c|}
\hline & \multicolumn{2}{|c|}{$\begin{array}{c}\text { Total } \\
N=57\end{array}$} & \multicolumn{2}{|c|}{$\begin{array}{c}\text { Treatment group } \\
(\text { SUD-T+PSA-T }) \\
(n=29)\end{array}$} & \multicolumn{2}{|c|}{$\begin{array}{l}\text { Control group } \\
(\text { SUD-T) } \\
(n=28)\end{array}$} & \multirow[b]{2}{*}{$t(d f)$} & \multirow[b]{2}{*}{$p$} & \multirow[b]{2}{*}{$d$} \\
\hline & Mean & $(S D)$ & Mean & $(S D)$ & Mean & $(S D)$ & & & \\
\hline \multirow[t]{2}{*}{ Age } & 41.5 & $(11.8)$ & 42.2 & $(11.9)$ & 40.8 & $(11.9)$ & $0.4(55)$ & .671 & 0.011 \\
\hline & $N$ & $(\%)$ & $n$ & $(\%)$ & $n$ & $(\%)$ & $\chi^{2}(d f)$ & $p$ & Phi \\
\hline \multicolumn{10}{|l|}{ Gender } \\
\hline Men & 31 & $(54.5)$ & 15 & $(51.7)$ & 16 & $(57.1)$ & \multirow{2}{*}{$0.1(1)$} & \multirow{2}{*}{.681} & \multirow{2}{*}{0.054} \\
\hline Women & 26 & $(45.6)$ & 14 & $(42.9)$ & 12 & $(42.9)$ & & & \\
\hline \multicolumn{10}{|l|}{ Marital status } \\
\hline Single & 27 & $(47.4)$ & 11 & $(37.9)$ & 16 & $(21.4)$ & \multirow{4}{*}{$4.2(3)$} & \multirow{4}{*}{.237} & \multirow{4}{*}{0.273} \\
\hline Married & 13 & $(22.8)$ & 7 & $(24.1)$ & 6 & $(57.1)$ & & & \\
\hline Separated/Divorced & 16 & $(28.1)$ & 11 & $(37.9)$ & 5 & $(17.9)$ & & & \\
\hline Widower & 1 & $(1.8)$ & 0 & $(--)$ & 1 & $(3.6)$ & & & \\
\hline \multicolumn{10}{|l|}{ Education level } \\
\hline No studies & 3 & (5.3) & 2 & (6.9) & 1 & (3.6) & \multirow{4}{*}{$2.2(3)$} & \multirow{4}{*}{.530} & \multirow{4}{*}{0.197} \\
\hline Primary & 18 & $(31.6)$ & 7 & $(24.1)$ & 11 & $(39.3)$ & & & \\
\hline Secondary & 29 & $(50.9)$ & 17 & $(58.6)$ & 12 & $(42.9)$ & & & \\
\hline University & 7 & $(12.3)$ & 3 & $(10.3)$ & 4 & $(14.3)$ & & & \\
\hline \multicolumn{10}{|l|}{ Employment situation } \\
\hline Employed & 23 & $(40.4)$ & 13 & $(44.8)$ & 10 & $(35.7)$ & \multirow{3}{*}{$0.4(2)$} & \multirow{3}{*}{.779} & \multirow{3}{*}{0.094} \\
\hline Unemployed & 32 & $(56.1)$ & 15 & $(51.7)$ & 17 & $(60.7)$ & & & \\
\hline Retired & 2 & (3.5) & 1 & $(3.4)$ & 1 & (3.6) & & & \\
\hline \multicolumn{10}{|c|}{ Substance motivating treatment } \\
\hline Alcohol & 23 & $(40.4)$ & 15 & $(51.7)$ & 8 & $(28.6)$ & \multirow{4}{*}{$4.6(3)$} & \multirow{4}{*}{.196} & \multirow{4}{*}{0.287} \\
\hline Cocaine & 14 & $(24.6)$ & 4 & $(13.8)$ & 10 & $(35.7)$ & & & \\
\hline Polyconsumption & 12 & $(21.1)$ & 6 & $(20.7)$ & 6 & $(21.4)$ & & & \\
\hline Other & 8 & $(14.0)$ & 4 & (13.8) & 4 & $(14.3)$ & & & \\
\hline \multicolumn{10}{|l|}{ Trauma } \\
\hline Physical abuse & 49 & $(86.0)$ & 23 & (79.3) & 26 & $(92.9)$ & $2.1(1)$ & .141 & 0.195 \\
\hline Sexual abuse & 25 & $(43.9)$ & 13 & $(44.8)$ & 12 & $(42.9)$ & $0.0(1)$ & .881 & 0.020 \\
\hline
\end{tabular}

SUD-T $=$ Substance use disorder treatment; PSA-T $=$ Physical and/or sexual abuse treatment

López-Goñi, J. J., Haro, B., Fernández-Montalvo, J., \& Arteaga, A. (2021). Impact of a trauma intervention on reducing dropout from substance use disorder treatment. Psychological Trauma: Theory, Research, Practice, and Policy. Advance online publication. https://doi.org/10.1037/tra0001127 
Table 2

Summary of the Trauma Intervention Programme

\begin{tabular}{ccc}
\hline Sessions & Content & Therapeutic techniques \\
\hline 1 & $\begin{array}{c}\text { Motivation for therapy } \\
\text { Acceptance of the basic principles of therapy }\end{array}$ & Motivational interview \\
$2-3$ & $\begin{array}{c}\text { Cognitive distortions related to traumatic event } \\
\text { Cond sexual abuse and addictions }\end{array}$ & $\begin{array}{c}\text { Education about trauma and its consequences } \\
\text { Cognitive revaluation }\end{array}$ \\
$4-5$ & Re-experiencing & Stop thinking and cognitive distraction \\
$4-5-6-7-8$ & Anxiety/stress & Relaxation \\
5 & Avoidance & Identification and exposure (when necessary) \\
$6-7$ & Social isolation & Development of hobbies \\
8 & Self-esteem & Cognitive revaluation \\
9 & Problem solving deficits & Problem solving training \\
10 & Summary of contents & Psychoeducation \\
\hline
\end{tabular}

Source: Based on Echeburúa \& Corral (1998)

López-Goñi, J. J., Haro, B., Fernández-Montalvo, J., \& Arteaga, A. (2021). Impact of a trauma intervention on reducing dropout from substance use disorder treatment. Psychological Trauma: Theory, Research, Practice, and Policy. Advance online publication. 
Table 3

Variables Related to Substance Use Disorder Treatment Completion

Logistic regression

Dependent variable $=$ SUD-T completion; $0=$ SUD-T failure; $1=$ SUD-T success

All participants $(n=57)$

\begin{tabular}{lllc}
\hline \multicolumn{1}{c}{ Variable } & OR & $p$ & $95 \%$ IC \\
\hline Completed PSA-T (Yes) & 3.3 & .036 & $(1.1-10.1)$ \\
Constant & 0.7 & .778 &
\end{tabular}

Adjusted R ${ }^{2}$

$\%$ Correctly classified 63.2

SUD-T $=$ Substance use disorder treatment; PSA-T $=$ Physical and/or sexual abuse treatment

López-Goñi, J. J., Haro, B., Fernández-Montalvo, J., \& Arteaga, A. (2021). Impact of a trauma intervention on reducing dropout from substance use disorder treatment. Psychological Trauma: Theory, Research, Practice, and Policy. Advance online publication. 
Table 4

Comparison of Psychopathological, Personality and Maladjustment Variables between Groups

\begin{tabular}{|c|c|c|c|c|c|c|c|c|c|c|}
\hline & \multicolumn{3}{|c|}{$\begin{array}{l}\text { Treatment group } \\
(\text { SUD-T+PSA-T) }\end{array}$} & \multicolumn{3}{|c|}{$\begin{array}{l}\text { Control group } \\
\text { (SUD-T) }\end{array}$} & \multirow[b]{2}{*}{$t$} & \multirow[b]{2}{*}{$(d f)$} & \multirow[b]{2}{*}{$p$} & \multirow[b]{2}{*}{$d$} \\
\hline & $\mathrm{n}$ & Mean & (SD) & $\mathrm{n}$ & Mean & (SD) & & & & \\
\hline \multicolumn{11}{|c|}{ EGS-R total (16-64) } \\
\hline Pre-treatment & 29 & 18.8 & $(9.8)$ & 28 & 17.2 & (10.6) & 0.5 & (55) & .571 & 0.151 \\
\hline Post-treatment & 24 & 8.2 & $(7.2)$ & 22 & 9.8 & $(7.5)$ & 0.7 & (44) & .453 & 0.224 \\
\hline Follow-up & 17 & 4.6 & $(5.1)$ & 16 & 7.8 & (5.4) & 1.7 & (31) & .090 & 0.590 \\
\hline \multicolumn{11}{|c|}{ EGS-R interference $(0-18)$} \\
\hline Pre-treatment & 29 & 8.4 & $(5.0)$ & 28 & 8.0 & $(5.6)$ & 0.2 & (55) & .791 & 0.071 \\
\hline Post-treatment & 24 & 3.5 & $(4.1)$ & 22 & 4.4 & $(5.0)$ & 0.6 & (44) & .505 & 0.199 \\
\hline Follow-up & 17 & 1.0 & $(1.4)$ & 16 & 3.6 & $(3.5)$ & 2.6 & $(19)^{*}$ & .014 & 0.872 \\
\hline \multicolumn{11}{|c|}{ SCL-90-R-GSI (1-99) } \\
\hline Pre-treatment & 29 & 71.5 & $(30.4)$ & 28 & 79.0 & (22.3) & 1.0 & (55) & .295 & 0.278 \\
\hline Post-treatment & 24 & 54.5 & $(31.1)$ & 22 & 60.7 & (27.5) & 0.7 & (44) & .478 & 0.212 \\
\hline Follow-up & 17 & 37.8 & $(23.1)$ & 16 & 57.6 & $(28.0)$ & 2.2 & (31) & .034 & 0.730 \\
\hline \multicolumn{11}{|c|}{ SCL-90-R-PSDI (1-99) } \\
\hline Pre-treatment & 29 & 68.3 & $(31.2)$ & 28 & 63.6 & (27.3) & 0.5 & (55) & .555 & 0.158 \\
\hline Post-treatment & 24 & 45.0 & (29.6) & 22 & 52.7 & (26.3) & 0.9 & (44) & .363 & 0.272 \\
\hline Follow-up & 17 & 36.0 & $(23.5)$ & 16 & 55.5 & (25.5) & 2.2 & (31) & .029 & 0.747 \\
\hline \multicolumn{11}{|c|}{ SCL-90-R-PST (1-99) } \\
\hline Pre-treatment & 29 & 70.0 & $(29.0)$ & 28 & 78.0 & $(22.1)$ & 1.1 & (55) & .245 & 0.309 \\
\hline Post-treatment & 24 & 58.8 & $(32.5)$ & 22 & 62.1 & (28.7) & 0.3 & (44) & .714 & 0.109 \\
\hline Follow-up & 17 & 40.8 & $(23.7)$ & 16 & 57.1 & (29.8) & 1.7 & (31) & .090 & 0.590 \\
\hline \multicolumn{11}{|l|}{ BIS-10 (0-132) } \\
\hline Pre-treatment & 29 & 58.3 & (19.9) & 28 & 54.6 & (16.3) & 0.7 & (55) & .449 & 0.202 \\
\hline Post-treatment & 24 & 45.1 & $(18.0)$ & 22 & 51.5 & (17.4) & 1.2 & (44) & .228 & 0.358 \\
\hline Follow-up & 17 & 36.4 & $(18.6)$ & 16 & 41.8 & (14.6) & 0.9 & (31) & .364 & 0.321 \\
\hline \multicolumn{11}{|l|}{ MS $(0-30)$} \\
\hline Pre-treatment & 29 & 20.2 & $(6.9)$ & 28 & 20.5 & $(5.1)$ & 0.1 & (55) & .857 & 0.048 \\
\hline Post-treatment & 24 & 9.7 & $(6.5)$ & 22 & 14.9 & $(7.0)$ & 2.5 & (44) & .014 & 0.715 \\
\hline Follow-up & 17 & 4.9 & $(3.8)$ & 16 & 11.6 & (7.9) & 3.0 & $(21)^{*}$ & .006 & 0.962 \\
\hline
\end{tabular}

SUD-T $=$ Substance use disorder treatment; PSA-T $=$ Physical and/or sexual abuse treatment;

EGS-R = Severity Posttraumatic Stress Disorder Scale - Revised; SCL-90-R = Symptom

Checklist; GSI = Global Severity Index; PSDI = Positive Symptom Distress Index; PST = Positive

Symptom Total; BIS-10 = Barratt Impulsiveness Scale; MS = Maladjustment Scale

\footnotetext{
* Variance between groups was not homogeneous. Student's t for not homogeneous variance was calculated.
}

López-Goñi, J. J., Haro, B., Fernández-Montalvo, J., \& Arteaga, A. (2021). Impact of a trauma intervention on reducing dropout from substance use disorder treatment. Psychological Trauma: Theory, Research, Practice, and Policy. Advance online publication. https://doi.org/10.1037/tra0001127 


\section{Table 5}

Results of Repeated-measures ANOVA (Pre, Post and 6-Month Follow-up)

\begin{tabular}{|c|c|c|c|c|c|c|c|c|c|c|c|c|c|c|c|}
\hline & \multicolumn{3}{|c|}{ ANOVA } & \multicolumn{4}{|c|}{ Pre-Post } & \multicolumn{4}{|c|}{ Pre-Follow } & \multicolumn{4}{|c|}{ Post-Follow } \\
\hline & $\mathrm{n}$ & $F$ & $p$ & $t$ & $(d f)$ & $p$ & $d$ & $t$ & $(d f)$ & $p$ & $d$ & $t$ & $(d f)$ & $p$ & $d$ \\
\hline \multicolumn{16}{|l|}{ EGS-R total (16-64) } \\
\hline Treatment group & 17 & 19.0 & .000 & 6.5 & (23) & .000 & 1.171 & 6.2 & (16) & .000 & 1.739 & 1.6 & (16) & .120 & 0.272 \\
\hline Control group & 16 & 14.5 & .000 & 5.0 & (21) & .000 & 0.984 & 3.9 & (15) & .001 & 1.722 & 0.6 & (15) & .540 & 0.364 \\
\hline \multicolumn{16}{|c|}{ EGS-R interference $(0-18)$} \\
\hline Treatment group & 17 & 17.8 & .000 & 4.6 & (23) & .000 & 0.207 & 5.6 & (16) & .000 & 0.994 & 2.4 & (16) & .027 & 0.740 \\
\hline Control group & 16 & 9.0 & .001 & 4.0 & (21) & .001 & 0.711 & 2.9 & (15) & .011 & 1.250 & -0.9 & $(15)$ & .375 & 0.233 \\
\hline \multicolumn{16}{|l|}{ SCL-90-R GSI (1-99) } \\
\hline Treatment group & 17 & 7.3 & .002 & 2.6 & (23) & .014 & 0.011 & 3.4 & (16) & .003 & 0.127 & 1.8 & (16) & .084 & 0.138 \\
\hline Control group & 16 & 8.4 & .001 & 4.3 & (21) & .000 & 0.663 & 3.1 & (15) & .007 & 0.761 & 0.4 & $(15)$ & .689 & 0.108 \\
\hline \multicolumn{16}{|l|}{ SCL-90-R PSDI (1-9 } \\
\hline Treatment group & 17 & 7.4 & .006 & 2.9 & (23) & .008 & 0.030 & 5.6 & (16) & .000 & 0.139 & 0.7 & (16) & .441 & 0.111 \\
\hline Control group & 16 & 0.4 & .655 & 2.5 & (21) & .019 & 0.416 & 0.6 & (15) & .518 & 0.318 & -0.1 & (15) & .930 & 0.111 \\
\hline \multicolumn{16}{|l|}{ SCL-90-R PST (1-99) } \\
\hline Treatment group & 17 & 4.4 & .020 & 1.8 & (23) & .074 & 0.056 & 2.3 & (16) & .030 & 0.093 & 1.7 & (16) & .094 & 0.154 \\
\hline Control group & 16 & 9.6 & .001 & 3.8 & (21) & .001 & 0.551 & 3.4 & (15) & .004 & 0.698 & 0.8 & (15) & .415 & 0.167 \\
\hline \multicolumn{16}{|l|}{ BIS-10 (0-132) } \\
\hline Treatment group & 17 & 10.5 & .001 & 2.7 & (23) & .010 & 0.03 & 3.7 & (16) & .002 & 0.139 & 1.7 & $(16)$ & .100 & 0.014 \\
\hline Control group & 16 & 4.3 & .022 & 0.9 & (21) & .360 & 0.174 & 2.5 & (15) & .023 & 0.318 & 1.8 & (15) & .078 & 0.668 \\
\hline \multicolumn{16}{|l|}{ MS (0-30) } \\
\hline Treatment group & 17 & 39.6 & .000 & 6.1 & (23) & .000 & 0.026 & 9.0 & (16) & .000 & 0.261 & 2.3 & (16) & .032 & 0.228 \\
\hline Control group & 16 & 8.4 & .001 & 3.1 & (21) & .005 & 0.790 & 3.9 & (15) & .001 & 1.110 & 1.2 & (15) & .244 & 0.410 \\
\hline
\end{tabular}

EGS-R = Severity posttraumatic stress disorder scale - revised; SCL-90-R = Symptom checklist;

GSI = Global severity index; PSDI = Positive symptom distress index; PST $=$ Positive symptom

distress; BIS-10 = Barratt Impulsiveness Scale; MS = Maladjustment Scale

López-Goñi, J. J., Haro, B., Fernández-Montalvo, J., \& Arteaga, A. (2021). Impact of a trauma intervention on reducing dropout from substance use disorder treatment. Psychological Trauma: Theory, Research, Practice, and Policy. Advance online publication. 


\section{Figure 1}

\section{Participant's Flow Diagram}

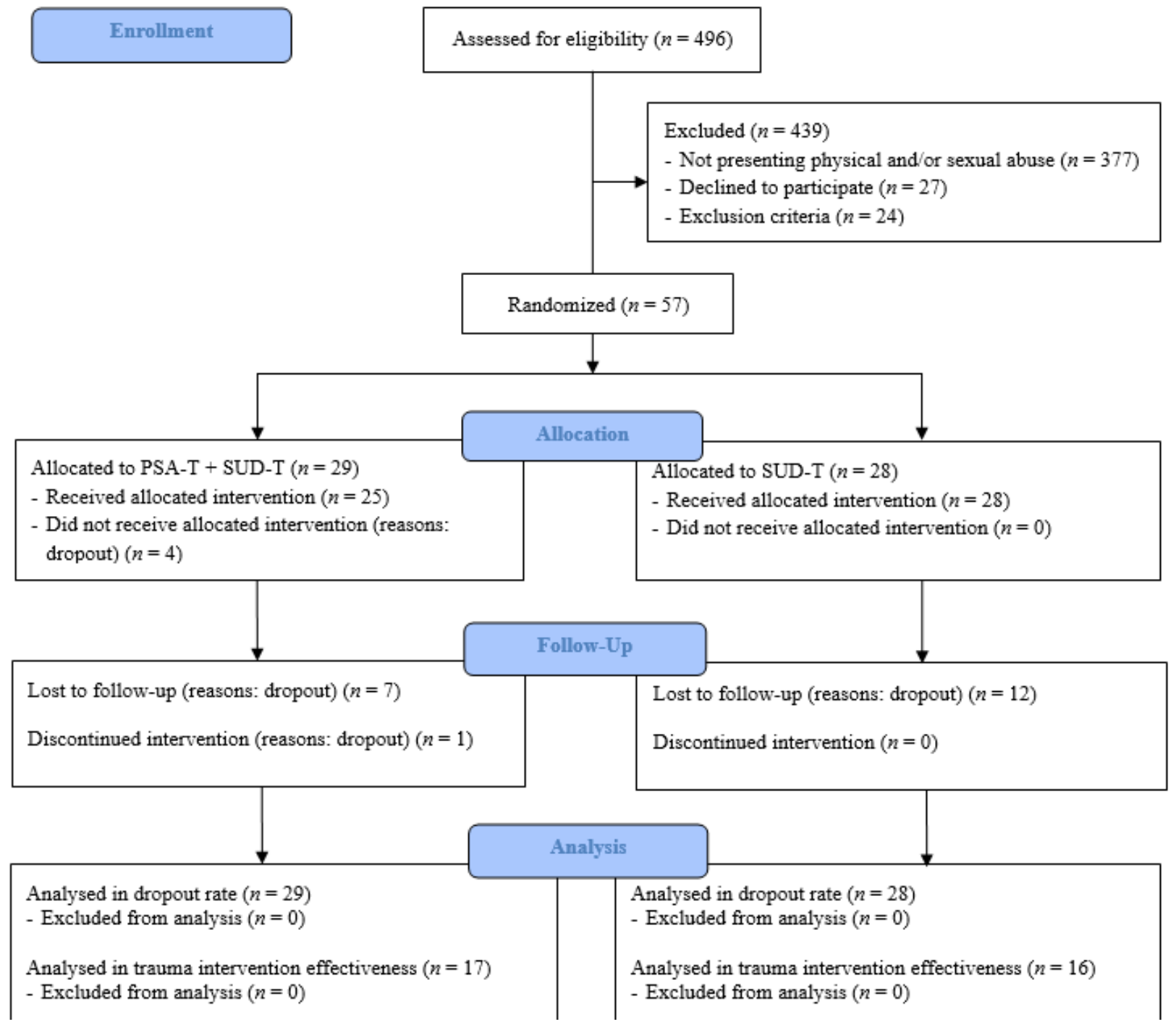

PSA-T: Physical and/or sexual abuse treatment; SUD-T: Substance use disorder treatment

López-Goñi, J. J., Haro, B., Fernández-Montalvo, J., \& Arteaga, A. (2021). Impact of a trauma intervention on reducing dropout from substance use disorder treatment. Psychological Trauma: Theory, Research, Practice, and Policy. Advance online publication. 